\title{
Osteopenia and osteoporosis in people living with HIV: multiprofessional approach
}

This article was published in the following Dove Press journal:

HIVIAIDS - Research and Palliative Care

7 December 20II

Number of times this article has been viewed

Ana Lucia Lei Munhoz Lima

Priscila Rosalba D de

Oliveira

Perola Grimberg Plapler

Flora Maria D Andrea

Marcolino

Eduardo de Souza Meirelles

André Sugawara

Riccardo Gomes Gobbi

Alexandre Leme Godoy

dos Santos

Gilberto Luis Camanho

Institute of Orthopedics and

Traumatology, Hospital das Clínicas,

University of São Paulo School of

Medicine, São Paulo, Brazil
Correspondence: Ana Lucia Lei

Munhoz Lima

Dr R Ovidio Pires de Campos, 333, sala

3I I A - CEP 05403-0 I0, São Paulo, Brazil

Tel +55 II 30696900

Fax +55 II 30696900

Email ccih.iot@hcnet.usp.br

\begin{abstract}
Increasing bone mineralization abnormalities observed among people living with HIV (PLWHIV) result from various factors relating to the host, the virus, and the antiretrovirals used. Today, HIV infection is considered to be a risk factor for bone mineralization disorders. The test most recommended for diagnosing osteoporosis is measurement of bone mineral density by means of dual energy X-ray absorptiometry at two sites. Osteoporosis treatment has the aims of bone mass improvement and fracture control. A combination of calcium and vitamin D supplementation may reduce the risk of fractures. Antiresorptive drugs act by blocking osteoclastic activity and reducing bone remodeling. On the other hand, bone-forming drugs stimulate osteoblastogenesis, thereby stimulating the formation of bone matrix. Mixedaction medications are those that are capable of both stimulating bone formation and inhibiting reabsorption. Antiresorptive drugs form the group of medications with the greatest quantity of scientific evidence confirming their efficacy in osteoporosis treatment. Physical activity is a health promotion strategy for the general population, but only preliminary data on its real value and benefit among PLWHIV are available, especially in relation to osteoporosis.
\end{abstract}

Keywords: osteoporosis, HIV/AIDS, diagnosis, treatment, exercise

\section{Introduction}

Life expectancy has increased significantly among people living with HIV (PLWHIV) since the introduction of highly active antiretroviral therapy (HAART). Living with this viral infection for prolonged periods, and with its treatment, has certain consequences. For example, osteoarticular abnormalities are increasingly observed among such patients and are being studied in greater detail with the aim of detecting their possible causes and determining the most appropriate therapeutic approach. Among these complex changes, diminished bone mineralization is observed in a large percentage of the patients, resulting from various factors relating to the host, the virus, and the antiretrovirals used. Bone is constantly remodeled through synchronism between its formation and reabsorption, but this may become deregulated through HIV infection. When bone mineralization decreases, osteopenia occurs and may progress to osteoporosis. ${ }^{1}$

According to the World Health Organization, the definitions of osteopenia and osteoporosis are based on results from bone densitometry, in which the patient's bone density is compared with the average for young adults, after adjusting for race and gender. ${ }^{2}$ The condition is defined as osteoporosis when the resulting relationship is below -2.5 times the standard deviation, and as osteopenia when the result is between -2.5 and -1.0 times the standard deviation. ${ }^{3}$ Patients should also be considered to present osteoporosis if fragility fractures occur, caused by minimal trauma. 


\section{HIV and bone metabolism}

Many authors have shown that PLWHIV have a high prevalence of these abnormalities, according to the criteria cited above. ${ }^{3-11}$ Currently, HIV infection is considered to be a risk factor for bone mineralization disorders, and therefore it should be recommended that all postmenopausal HIVpositive women and all HIV-positive men aged 49 years and over should be investigated for such disorders. ${ }^{12}$

Many factors have been reported to cause osteopenia in PLWHIV. Among these are direct effects from the virus on osteogenic cells; persistent activation of pro-inflammatory cytokines, especially tumor necrosis factor alpha (TNF $\alpha$ ) and interleukin-1; changes to vitamin D metabolism, with deficiency of 1,25 dihydroxyvitamin $\mathrm{D}$; and participation of mitochondrial abnormalities relating to lactic acidemia and the development of opportunistic diseases. ${ }^{5-7}$

Studies on the influence of antiretroviral treatment show that the relative risk is greater when protease inhibitors are used. Studies have also shown that indinavir inhibits bone formation and ritonavir inhibits osteoclast differentiation and function. . $^{2,6-9,13}$ Other factors may contribute towards accelerating the bone loss, such as nutritional deficiencies, low serum calcium levels, immobilization, hypogonadism, hyperthyroidism, hyperparathyroidism, kidney failure, opioid or heroin use, corticosteroid use, postmenopausal status among women, and alcohol intake greater than $16 \mathrm{~g} / \mathrm{day}^{2,6,7,10-12}$

The most important risk factors associated with bone loss in HIV-positive patients are advanced age, smoking, Caucasian race, low weight, and low body mass index (BMI). These risk factors, in this order of frequency (highest to lowest), are the ones most commonly cited in studies, even in cases of long-duration infection. ${ }^{14}$

In a meta-analysis on ten studies, Bolland et al ${ }^{15}$ compared the impact of BMI on bone loss in HIV patients undergoing antiretroviral treatment. They concluded that the main factor that explained the difference in bone mineral density (BMD) between infected and normal individuals was low BMI. Special attention needs to be paid to alcohol consumption, which favors lactic acidosis, particularly among patients with hepatitis virus coinfection. Other factors that increase the risk of bone loss among PLWHIV include malnutrition; excessive weight loss; phosphocalcium disorders such as hypovitaminosis $\mathrm{D}$; and hypogonadism, which is found in $20 \%$ to $30 \%$ of HIV-positive men. ${ }^{16,17}$

HIV infection also modifies bone metabolism through several inflammatory factors, ie, direct effects of the virus on bone cells. ${ }^{18} \mathrm{HIV}$-positive patients have very high levels of anti-TNF $\alpha$. The pro-inflammatory cytokines secreted by the T lymphocytes of HIV-positive patients affect their bone metabolism through inhibiting osteoblasts and activating osteoclasts, and one of the mediators of these effects is the RANK-L (receptor activator of NF-kappaB - ligand) signaling pathway. ${ }^{19}$ The role of HIV in RANK-L activation (described in 2005) shows that people living with HIV have very high levels of RANK-L. TNF $\alpha$ may be implicated in inhibition of 1- $\alpha$ hydroxylase, which in turn alters the metabolism of vitamin D. ${ }^{20}$ Table 1 shows the main known effects of HIV on osteoblasts and osteoclasts. ${ }^{21}$

\section{Assessment and diagnosis}

The clinical evaluation of patients with suspected osteoporosis should include an overall assessment of their health, from physical activities to diseases that secondarily induce decreased bone mineral density. The test most recommended for diagnosing osteoporosis is measurement of bone mineral density (BMD) using DEXA (dual energy X-ray absorptiometry) at two sites, usually the proximal femur and the lumbar spine. If these sites cannot be tested for any reason, the forearm (radius) is used. ${ }^{22} \mathrm{BMD}$ is calculated through this examination by dividing the bone mineral mass (in grams) by the surface area of the bones tested (in $\mathrm{cm}^{2}$ ). The result is then compared with two populations:

1. Young adult population of the same gender. The number of standard deviations of difference in relation to this population is described as the T-score. If the score is $<-2.5$, a diagnosis of osteoporosis is made, while if it is between -2.5 and -1.0 , the diagnosis is considered to be osteopenia. Findings of $\geq-1.0$ are considered to be normal BMD.

2. Population matched according to age and gender. The number of standard deviations of difference in relation to this population is described as the $Z$-score. Scores of $\leq-2.0$ standard deviations are considered to be abnormal.

$\mathrm{T}$-scores are generally used as the standard for patients over the age of 50 years, and $Z$-scores for those $<50$ years of age. ${ }^{23}$ Although the use of the BMD scan for screening

Table I Effects of HIV on osteoblasts and osteoclasts

\begin{tabular}{lll}
\hline Bone cell & Effect & Mechanism \\
\hline Osteoblast & $\uparrow$ apoptosis & TNF- $\alpha$ autocrine/paracrine pathway \\
& $\uparrow$ activity & $\downarrow$ calcium deposition and $\downarrow$ \\
& $\downarrow$ differentiation & $\begin{array}{l}\text { alkaline phosphatase activity } \\
\text { Deviation to the adipose cell line }\end{array}$ \\
Osteoclast & $\uparrow$ differentiation & $\begin{array}{l}\text { Upregulation of the macrophage } \\
\text { colony-stimulating factor and RANK-L }\end{array}$ \\
& $\uparrow$ activity & .
\end{tabular}

Note: Adapted from Borderi M Borderi M, Gibellini D, Vescini F, et al. Metabolic bone disease in HIV infection. AIDS. 2009;23(II):1297-1310 with permission of the publisher. ${ }^{21}$ 
young populations is controversial, this is now a feasible and widely available method of diagnosing this disease.

Identifying individuals at risk for osteoporosis helps decide whether or not to perform a BMD investigation. Based on general population recommendations, a BMD investigation should be done upon the occurrence of any of the following:

- Women $>65$ years;

- Men > 70 years;

- Postmenopausal women $>50$ years with any risk factor for fractures;

- People with a fracture occurring after 50 years of age;

- Prolonged corticosteroid use;

- People with conditions inducing loss of bone mass;

- People taking medications that induce loss of bone mass. $^{24,25}$

PLWHIV fit in the last two categories at least, and therefore should be considered at risk for osteoporosis and investigated with DEXA.

The following laboratory tests should be carried out as the minimum recommended investigation in cases of osteopenia/osteoporosis, to identify secondary causes and to aid in scheduling the ideal treatment: ${ }^{24}$

- complete hemogram;

- serum calcium and phosphorus;

- renal function;

- hepatic function;

- total protein and fractions;

- total cholesterol and fractions;

- alkaline phosphatase;

- serum vitamin D (1,25 dihydroxyvitamin D);

- additional tests depending on the patient: parathormone, protein electrophoresis, thyroid-stimulating hormone, ertithrocyte sedimentation rate, 24-hour urine for calcium, testosterone, or prolactin.

Other tests that could be used include tests for so-called bone resorption markers. The most important of these is CTx (carboxy-terminal telopeptide of type I collagen). A decrease in this marker in the blood can be used as an indicator of success in treating osteoporosis, and it is especially useful because it presents changes earlier than densitometry. Bone formation markers such as osteocalcin, total alkaline phosphatase, and N-terminal propeptide of type I procollagen can be used in a similar way. ${ }^{25-27}$

\section{Osteoporosis treatment for PLWHIV}

For all patients, whether they are HIV-positive or not, osteoporosis treatment has the aims of bone mass improvement and fracture control. Any intervention should also have the aims of diminishing pain and physical limitations and improving self-esteem and self-confidence, which are the main factors responsible for distress among these patients. General advice on hygiene and diet, as demonstrated in Table 2, should be provided from the outset of the treatment, or used as preventive measures. ${ }^{15}$

Therapies for treating and preventing osteoporosis began with the use of estrogen alone or in combination with a progestin. New medications have now appeared, and many others are expected to become available in the near future. The main types of therapy that currently exist are described below. ${ }^{28}$

\section{Adequate calcium and vitamin $D$ intake}

A combination of calcium and vitamin D supplementation may reduce the risk of fractures safely and cheaply. Adequate calcium intake throughout life is necessary in order to achieve peak bone mass and subsequently to maintain bone health. The skeleton contains $99 \%$ of the body's calcium deposits. When calcium intake is inadequate, bone tissue is reabsorbed from the skeleton in order to keep the serum calcium levels constant. Calcium intake recommendations are presented in Table 3. ${ }^{29}$ Intake higher than the recommended levels has limited benefit and may increase the risk of developing kidney stones or cardiovascular disease. ${ }^{30}$

Current evidence indicates that there is no specific recommendation for calcium supplementation for PLWHIV and therefore this population should receive the same age and gender recommendations as the general population.

\section{Vitamin D}

Vitamin D is fundamental for calcium absorption, bone health, muscle performance, balance and reduced risk of falls. The recommended vitamin D intake for adults over the age of 50 years is 800 to $1000 \mathrm{IU} /$ day, which will maintain serum vitamin D at an adequate level of $30 \mathrm{ng}$ /day. In patients with osteoporosis the dose of vitamin D should be enough to ensure that circulating levels of 1,25 dihydroxyvitamin D reach a threshold of $50 \mathrm{nmol} / \mathrm{L} .{ }^{31}$ The main vitamin D-rich foods are egg yolk, saltwater fish (salmon, tuna, and sardines),

Table 2 General measures for prevention and treatment of osteoporosis

Increased calcium intake (milk and derivatives).

Reduced salt, coffee, and alcoholic drink intake.

Optimization of physical activity.

Exposure to the sun.

Detection and treatment of the associated disease (AIDS). 
Table 3 Recommended calcium and vitamin D intake ${ }^{29}$

\begin{tabular}{lll}
\hline Life-stage group & $\begin{array}{l}\text { Calcium } \\
\text { (mg/day) }\end{array}$ & $\begin{array}{l}\text { Vitamin D } \\
\text { (IU/day) }\end{array}$ \\
\hline Infants 0 to 6 months & 200 & 400 \\
Infants 6 to I2 months & 260 & 400 \\
I to 3 years old & 700 & 600 \\
4 to 8 years old & 1,000 & 600 \\
9 to I3 years old & 1,300 & 600 \\
14 to 18 years old & 1,300 & 600 \\
19 to 30 years old & 1,000 & 600 \\
3I to 50 years old & 1,000 & 600 \\
51 - to 70-year-old males & 1,000 & 600 \\
51 - to 70-year-old females & 1,200 & 600 \\
$>70$ years old & 1,200 & 800 \\
14 to 18 years old, & 1,300 & 600 \\
Pregnant/Lactating & & 600 \\
19 to 50 years old, & 1,000 & \\
Pregnant/Lactating & & \\
\hline
\end{tabular}

Notes: Vitamin D plays an important role in calcium absorption and bone health. It is made in the skin after exposure to sunlight and can also be obtained through the diet. Although many people are able to obtain enough vitamin $D$ naturally, vitamin D production decreases in the elderly, in people who are housebound or do not get enough sun, and in some people with chronic neurological or gastrointestinal diseases. These individuals and others at risk for vitamin $D$ deficiency may require vitamin $D$ supplementation. The recommended daily intake of vitamin $D$ is 400 IU for infants; children, and adults up to age 70 should get $600 \mathrm{IU}$ daily. Men and women age 70 and older should get $800 \mathrm{IU}$ of vitamin $\mathrm{D}$ daily. Reprinted with permission from Dietary Reference Intakes for Calcium and Vitamin D, 20I I, 20II by the National Academy of Sciences, Courtesy of National Academies Press, Washington, DC. ${ }^{29}$

nuts (eg, walnuts, almonds, hazelnuts, Brazil nuts) and liver. Some calcium supplements and most multivitamin pills also contain vitamin D. Patients who present with poor absorption need higher levels. ${ }^{32,33}$ When 1,25 dihydroxyvitamin D levels are low, cholecalciferol supplementation is required in order to normalize these values.

Regular physical activity and quitting smoking are important for reducing the risk of fractures, as is reducing excessive alcohol consumption (three or more units per day).

\section{Pharmacological treatment}

The medications that act on bone metabolism, and form part of the therapeutic arsenal against osteoporosis, are classified as follows and summarized in Table 4:

- Anticatabolic or antiresorptive

- Bone-forming or anabolic

- Mixed action

Antiresorptive drugs act by blocking osteoclastic activity and reducing bone remodeling. On the other hand, boneforming drugs stimulate osteoblastogenesis and increase the formation of bone matrix. Mixed-action drugs are capable of both stimulating bone formation and inhibiting reabsorption. Antiresorptive drugs are the group for which the greatest quantity of scientific evidence confirming their effectiveness for treating osteoporosis exists. ${ }^{34}$

\section{Anticatabolic or antiresorptive drugs}

Hormone therapy

Hormone therapy has been approved by the US Food and Drug Administration (FDA) in the United States for osteoporosis prevention and for relief of the vasomotor symptoms and vulvovaginal atrophy associated with the menopause. Studies have shown that women treated with a combination of estrogen and progestogen for 5 years presented a $34 \%$ reduction in the risk of vertebral and hip fracture and a $23 \%$ reduction in the risk of nonvertebral fractures. ${ }^{35}$ However, neither the FDA nor the European Foundation for Osteoporosis and Bone Disease recommend this therapy as the first choice for preventing or treating osteoporosis. Young women and postmenopausal women living with HIV require special attention because of the associated hormonal changes and because of the greater risk of fractures. ${ }^{16}$

\section{Bisphosphonates}

The bisphosphonates most used are alendronate, risedronate, ibandronate, and zoledronate. Although all are pyrophosphate analogs and reduce bone reabsorption, they differ from each other in terms of their mineral affinity and biochemical action on bone cells. Clinical studies on bisphosphonates have shown different results on the speed with which antifracture action begins; their effectiveness at different skeletal sites; and the durability and reversibility of their effects. For this reason, the documented reductions in vertebral and nonvertebral fractures and the indications approved by the FDA differ according to the type of bisphosphonate. Several studies are in progress with the aim of assessing fracture prevention using alendronate and risedronate.

Alendronate: used at a dose of $70 \mathrm{mg} / \mathrm{week}$. This provides a $50 \%$ reduction in the incidence of vertebral, nonvertebral, and femoral fractures in non-HIV-positive osteoporotic patients. Although not extensively studied in PLWHIV, Lin and Rieder identified 3 open randomized studies showing that alendronate used in association with calcium and vitamin $\mathrm{D}$ had a beneficial effect on the BMD of osteopenic HIV-positive patients for 1 to 2 years, ie, similar to the

Table 4 Medications used in treating osteoporosis, according to their active agent

\begin{tabular}{lll}
\hline Antiresorptive drugs & Bone-forming drugs & Mixed-action drugs \\
\hline Hormone therapy & Teriparatide & Strontium ranelate \\
SERMs & & \\
Bisphosphonates & & \\
Calcitonin & & \\
\hline
\end{tabular}

Abbreviation: SERMs, selective estrogen receptor modulators. 
results obtained in studies on postmenopausal osteoporosis. ${ }^{36}$ However, these studies only covered 2-year periods and the risk of fracture could not be observed. McComsey et al showed that in HIV-positive men and women with lower BMD, alendronate increased the BMD of the lumbar spine and femoral neck when administered with adequate quantities of calcium and vitamin $\mathrm{D}$, and that adverse gastrointestinal events were well tolerated. ${ }^{37}$

Risedronate: used at a dose of $35 \mathrm{mg} /$ week. Recently, risedronate administered once a month $(150 \mathrm{mg})$ was approved. A comparative study between risedronate $5 \mathrm{mg} /$ day and $150 \mathrm{mg} /$ month demonstrated that the monthly dose was comparable with the daily dose in terms of safety and efficacy for treating postmenopausal women with osteoporosis. It has been shown to reduce the incidence of vertebral, nonvertebral, and femoral fractures by $50 \%$. Its action is rapid and takes place after 6 months of use..$^{38}$ For this reason, it can be recommended for patients who are at a high risk of new fractures. In addition to indications for prevention and treatment of vertebral and nonvertebral fractures in postmenopausal women; risedronate is also indicated for treating male osteoporosis and for maintaining and increasing the bone mass of patients who are using systemic corticoids. The particular features of this bisphosphonate indicate that this drug starts to act quickly and is an option for all patients, including HIVpositive individuals despite the lack of specific evidence for this population.

Zoledronate: Used at a dose of $5 \mathrm{mg}$, with intravenous infusion over a 15-minute period once a year, zoledronate has been found to reduce the incidence of vertebral fractures by $70 \%$ and hip fractures by $40 \%$, in patients with osteoporosis, but not specifically among HIV-positive individuals. It has also been found to reduce the risks of fractures and mortality when administered a few days after the first hip fracture. The side effects are similar to those of all other oral bisphosphonates, with the advantage that it does not cause gastrointestinal problems, inflammation of the esophagus, or peptic ulcers. There have been reports of osteonecrosis of the mandible, especially in cancer patients who are using intravenous bisphosphonates. Patients should receive high doses of vitamin D and calcium before receiving zoledronate, in order to reduce the possibility of developing hypocalcemia. Bolland et al showed that an annual infusion of zoledronate was effective in terms of densitometry results among osteopenic HIV-positive men. ${ }^{39}$ Another small clinical trial confirmed these findings in HIV-positive men and women, and also showed reduction in bone resorption markers in the zoledronate group. ${ }^{40}$

\section{Bone-forming or anabolic drugs}

Teriparatide (PTH)

This drug has been approved for postmenopausal osteoporosis treatment among women who are at high risk of developing fractures, and it should be administered daily by means of subcutaneous injection. PTH at a dose of 20 micrograms/day reduces the risk of vertebral fractures by $65 \%$ and nonvertebral fractures by $53 \%$, among patients treated for 18 months. ${ }^{41}$ No data are available on its efficacy and safety when used for longer periods, and there are few reports on HIV-positive patients.

\section{Mixed-action drugs}

\section{Strontium ranelate}

Strontium is incorporated into the bone and seems to have double action on bone tissue: it stimulates formation and reduces reabsorption. In patients with osteoporosis, strontium ranelate produces increased levels of biochemical markers for bone formation and decreased levels of the markers for reabsorption. It increases bone density by $14.4 \%$ in the lumbar spine and by $8.3 \%$ in the femoral neck. ${ }^{42}$ There are no studies on this drug among HIV-positive patients.

\section{Denosumab}

Denosumab is a human monoclonal antibody, recently been approved by the FDA. It acts by inhibiting the action of RANK-L, thereby inhibiting the action of osteoclasts, their differentiation, and survival. In a recent study among men with prostate cancer and androgen deprivation, there was a $5.6 \%$ increase in bone mass and a decrease in the incidence of fractures over a 36-month period. ${ }^{43-46}$ There are no studies on HIV-positive patients, but these findings suggest that it may be possible to use this drug to treat HIV-related bone mass losses. However, the immunological consequences of inhibiting RANK in HIV-positive patients are unknown and should be studied.

In summary, the only drugs with adequately designed studies for HIV-positive population are alendronate and zoledronate, apparently with similar results as previous studies for the general osteoporotic population. Studies with other drugs are currently in progress. FDA Advisory Committee Reviews Prolia Thousand Oaks, California, August 13/ PRNewswire-FirstCall/-Amgen Inc issued the following statement on the outcome of today's meeting with the US Food and Drug Administration (FDA) Advisory Committee for Reproductive Health Drugs (ACRHD) to review the potential use of Prolia (denosumab) for the prevention and treatment of postmenopausal osteoporosis and the prevention 
and treatment of bone loss in patients undergoing hormone ablation for either prostate cancer or breast cancer. FDA recommended and approved.

Finally, the panel recommended that Prolia have a Risk Evaluation and Mitigation Strategy (REMS), which could include a medication guide and a healthcare provider communications plan.

Often referred to as the "silent epidemic," osteoporosis is a global problem that is increasing in significance as the population of the world both increases and ages.

\section{Nondrug intervention}

Rigorous, prolonged adherence to HAART increases the survival of PLWHIV, but does not exempt them from a variety of complications, such as osteoporosis or osteopenia. ${ }^{46-48}$

Despite the real risk, osteoporosis-related fractures in PLWHIV remain little reported. It has been estimated that this will become a public health problem if measures are not taken. ${ }^{49,50}$

Physical activity is a health promotion strategy for the general population, but only preliminary data on its real value and benefit among PLWHIV is available, especially in relation to osteoporosis..$^{51,52}$

The literature increasingly shows evidence that regular physical activity of light to moderate intensity is safe and reduces pain, incapacity, and cardiovascular risk in the 1 population. ${ }^{53,54}$

Physical activity has also been correlated with improved quality of life, functional independence, aerobic capacity, and positive psychological changes. It is effective for preventing and treating osteoporosis and falls. ${ }^{55}$

There is no consensus on the role of exercise among PLWHIV with osteoporosis. Given that cardiovascular disease is a frequent cause of general mortality, a small increase in cardiac risk would significantly increase the morbiditymortality in the HIV-infected subgroup. Physical activity is indicated at least with the aim of minimizing the cardiac risk among PLWHIV. ${ }^{51}$

Impact, weight offloading, muscle strengthening, balance, and coordination exercises that are performed regularly have been shown to provide benefits for individuals with osteoporosis and osteopenia, through improving their performance and functionality in day-to-day activities, improving their BMD in the spine and hips and reducing their risk of falling. ${ }^{51,52}$

Other physical interventions include the use of vibratory platforms, functional electrical stimulation, laser, and ultrasound. However, even though the data show that these interventions have some benefit, they cannot be used as the only therapy or to the detriment of drug interventions or physical activity. These interventions may be useful for individuals with limitations or with contraindications for the current habitual treatments. ${ }^{56}$

Treating osteoporosis has the ultimate aim of preventing serious fractures such as in the hip and spine. Other interventions that diminish the risk of falls are also important. In this respect, adaptation of the environment through installation of adequate lighting, handrails, safety barriers, and appropriate flooring has become more prominent, as well as the use of orthoses and walking aids such as special footwear, walking sticks, walking frames, and crutches, which increase the individual's support base, sustainment, and proprioception.

Although PLWHIV are usually younger than the general population with osteoporosis and therefore less prone to falls, this population is growing older, and together with HIV-related conditions as lipodystrophy and hypogonadism, which induce muscle mass loss, prevention of falls cannot be neglected. Besides, PLWHIV are much more active and are exposed to traumas, unlike the elderly population.

While science seeks to identify the best way of managing osteoporosis among PLWHIV, these individuals continue to live and need rapid answers to ensure that their plans for life can continue with as little interference as possible from any comorbidities and complications from dysfunctional bone tissue that may be present. Despite the lack of specific data, the requirements of PLWHIV cannot go unmet and without guidance. Physical activity can be recommended as a safe and biologically plausible intervention for preventing falls and for improving BMD and bone quality.

\section{Disclosure}

Ana Lucia Lei Munhoz Lima declares that she received support from Merck Sharp and Dohme, Sanofi-Aventis, Bayer Schering Pharma, and Gilead Laboratory (represented by United Medical in Brazil) for participating in meetings and lectures.

Priscila Rosalba D de Oliveira declares that she received support from Merck Sharp and Dohme, and Bayer Schering Pharma for participating in meetings and lectures.

Flora Maria D'Andrea Marcolino declares that she received support from Pfizer, Roche, Astra Zeneca, and Lilly for conducting clinical research.

Eduardo de Souza Meirelles declares that he received support from the Servier Laboratory for presenting lectures.

Perola G Plapler declares that she received support from Merck Sharp and Dohme Corp, Sanofi-Aventis, Servier, GlaxoSmithKline, and SEM Lab, Inc, for lectures and clinical investigations. 


\section{References}

1. Lima AL, Zumiotti AV, Camanho GL, et al. Osteoarticular complications related to HIV infection and highly active antiretroviral therapy. Braz J Infect Dis. 2007;11(4):426-429.

2. Amorosa V, Tebas P. Bone disease and HIV Infection. Clin Infect Dis. 2006;42(1):108-114.

3. Bruera D, Luna N, David DO, Bergoglio LM, Zamudio J. Decreased bone mineral density in HIV-infected patients is independent of antiretroviral therapy. AIDS. 2003;17(13):1917-1923.

4. Delaunay C, Loiseau-Peres S, Benhamou CL. Osteopenia and human immunodeficiency virus. Joint Bone Spine. 2002;69(2):105-108.

5. Dolan SE, Huang JS, Killilea KM, Sullivan MP, Aliabadi N, Grinspoon S. Reduced bone density in HIV-infected women. AIDS 2004;18(3):475-483.

6. Jain RG, Lenhard JM. Select HIV protease inhibitors alter bone and fat metabolism ex vivo. J Biol Chem. 2002;277(22):19247-19250.

7. Mora S, Sala N, Bricalli D, Zuin G, Chiumello G, Viganò A. Bone mineral loss through increased bone turnover in HIV-infected children treated with highly active antiretroviral therapy. AIDS. 2001;15(14): 1823-1829.

8. Mora S, Zamproni I, Beccio S, Bianchi R, Giacomet V, Viganò A. Longitudinal changes of bone mineral density and metabolism in antiretroviral-treated human immunodeficiency virus-infected children. J Clin Endocrinol Metab. 2004;89(1):24-28.

9. Tan BM, Nelson RP Jr, James-Yarish M, Emmnueal P, Schurman SJ. Bone metabolism in children with human immunodeficiency virus infection receiving highly active anti-retroviral therapy including a protease inhibitor. J Pediatr. 2001;139(3):447-451.

10. Grijsen ML, Vrouenraets SM, Steingrover R, et al. High prevalence of reduced bone mineral density in primary HIV-1-infected men. AIDS 2010;24(14):2233-2238.

11. Sharma A, Flom PL, Weedon J, Klein RS. Prospective study of bone mineral density changes in aging men with or at risk for HIV infection. AIDS. 2010;24(15):2337-2345.

12. McComsey GA, Tebas P, Shane E, et al. Bone disease in HIV infection: a practical review and recommendations for HIV care providers. Clin Infect Dis. 2010;51(8):937-946.

13. Mondy K, Tebas P. Emerging bone problems in patients infected with human immunodeficiency virus. Clin Infect Dis. 2003;36(Suppl 2): S101-S105.

14. Szejnfeld VL. Epidemiologia da osteoporose e fraturas In: Szejnfeld V. Osteoporose: Diagnóstico e Tratamento. São Paulo: Sarvier; 2000:63-74.

15. Bolland MJ, Grey AB, Gamble GD, Reid IR. Low body weight mediates the relationship between HIV infection and low bone mineral density: a metaanalysis. J Clin Endocrinol Metab. 2007:92(12):4522-4528.

16. Kopicko JJ, Momodu I, Adedokum A, Hoffman M, Clark RA, Kissinger P. Characteristics of HIV-infected men with low serum testosterone levels. Int J STD AIDS. 1999;10(12):817-820.

17. Carr A, Miller J, Eisman JA, Cooper D. Osteopenia in HIV infected men: association with asyntomatic lactic academia and lower weight pre antiretroviral therapy. AIDS. 2001;15(6):703-709.

18. Amiel C, Ostertag A, Slama L, et al. BMD is reduced in HIV-infected men irrespective of treatment. J Bone Miner Res. 2004;19(3):402-409.

19. Pakruddin JM, Laurence J. HIV-1 Vpr enhances production of receptor of actived NF-KappaB ligant (RANKL) via potentiation of glucocorticoid receptor activity. Arch Virol. 2005;150(1):67-78.

20. Haug CJ, Aukrust P, Haug E, Morkrid L, Muller F, Froland SS. Severe deficiency of 1.25-dihydroxyvitamin D3 in human immunodeficiency virus infection: association with immunological hyperactivity and only minor changes in calcium homeostasis. J Clin Endocrinol. Metab. 1998;83(11):3832-3838.

21. Borderi M, Gibellini D, Vescini F, et al. Metabolic bone disease in HIV infection. AIDS. 2009;23(11):1297-1310.

22. Castel H, Bonneh DY, Sherf M, Liel Y. Awareness of osteoporosis and compliance with management guidelines in patients with newly diagnosed low-impact fractures. Osteoporosis Int. 2001; 12(7): 559-564.
23. Jennings LA, Auerbach AD, Maselli J, Pekow PS, Lindenauer PK, Lee SJ. Missed opportunities for osteoporosis treatment in patients hospitalized for hip fracture. J Am Geriatr Soc. 2010;58(4):650-657.

24. Elliot-Gibson V, Bogoch ER, Jamal SA, Beaton DE. Practice patterns in the diagnosis and treatment of osteoporosis after a fragility fracture: a systematic review. Osteoporosis Int. 2004;15(10):767-778.

25. National Osteoporosis Foundation. Clinician's Guide to Prevention and Treatment of Osteoporosis. Washington, DC, National Osteoporosis Foundation, 2008. www.nof.org/physguide. Accessed February 18, 2010.

26. Tebas P, Powderly WG, Claxton S, et al. Accelerated bone mineral loss in HIV-infected patients receiving potent antiretroviral therapy. AIDS. 2000;14(4):F63-F67.

27. Negredo E, Gel E, Arisa ER, et al. Bone mineral density (BMD) in HIV1-infected patients. In: Program and Abstracts of the 8th Conference on Retroviruses and Opportunistic Infections. Chicago, Washington, DC: Foundation for Retroviruses and Human Health; 2001:232. [Abstract 626.]

28. Rossouw JE, Anderson GL, Prentice RL, et al. Risks and benefits of estrogen plus progestin in healthy postmenopausal women: principal results from the Women's Health initiative randomized controlled trial. JAMA. 2002;288(3):321-333.

29. National Academy of Sciences. Dietary Reference Intakes for Calcium and Vitamin D, 2011. Washington DC: The National Academies Press; 2011. Available from: http://www.niams.nih.gov/Health_Info/Bone/ Bone_Health/Nutrition/default.asp. Accessed June 9, 2011.

30. Chapuy MC, Pamphile R, Paris E, et al. Combined calcium and vitamin D3 supplementation in elderly women: confirmation of reversal of secondary hyperparathyroidism and hip fracture risk: the Decalyos II study. Osteoporos Int. 2002;13(3):257-264.

31. Hanley DA, Cranney A, Jones G, et al. Vitamin D in adult health and disease: a review and guideline statement from Osteoporosis Canada. CMAJ. 2010;182(12):E610-E618.

32. Molimard R, Postec J, Pautas C, Bégué A, Carbonnier J, Delabeye B. Digestive absorption of calcium phosphates in man. Presse Med. 1985;14(45):2283-2286.

33. Autier P, Gandini S. Vitamin D supplementation and total mortality: a meta-analysis of randomized controlled trials. Arch Intern Med. 2007;167(16):1730-1737.

34. Pinheiro MM, Castro ML, Calcio e outros minerais. In: Szejnfeld VL, editor. Osteoporose: Diagnostico e Tratamento. São Paulo: Sarvier; 2000:302-320.

35. Institute of Medicine/Food and Nutrition Board. Dietary reference intakes: applications in dietary assessment. Washington: National Academy Press, 2001:306.

36. Lin D, Rieder MJ. Interventions for the treatment of decreased bone mineral density associated with HIV infection. Cochrane Database Syst Rev. 2007:CD.005645.

37. McComsey GA, Kendall MA, Tebas P, et al. Alendronate with calcium and vitamin D supplementation is safe and effective for the treatment of decreased bone mineral density in HIV. AIDS. 2007,21(18):2473-2482.

38. Russell RG, Watts NB, Ebetino FH, Rogers MJ. Mechanisms of action of biphosphonates: similarities and differences and their potential influence on clinical efficacy. Osteoporosis Int. 2008;19(6):733-759.

39. Bolland MJ, Grey AB, Horne AM, Briggs SE, Thomas MG, Ellis-Pegler RB. Annual zoledronate increases bone density in highly active antiretroviral therapy-treated human immunodeficiency virus-infected men: a randomized controlled trial. J Clin Endocrinol Metab. 2007;92(4):1283-1288.

40. Huang J, Meixner L, Fernandez S, McCutchan JA. A double-blinded, randomized controlled trial of zoledronate therapy for HIV-associated osteopenia and osteoporosis. AIDS. 2009;23(1):51-57.

41. Borba VZ, Mañas NC. The use of PTH in the treatment of osteoporosis. Arq Bras Endocrinol Metabol. 2010;54(2):213-219.

42. Sainz M, Del Pozo JG, Arias LH, Carvajal A. Strontium ranelate may cause alopecia. BMJ. 2009;338:b1494.

43. McClung MR, Lewiecki EM, Cohen SB, et al. Denosumab in postmenopausal women with low bone mineral density. $N$ Engl J Med. 2006;354(8):821-831. 
44. Rietstchel P, Corcoran C, Stanley T, Basgoz N, Klibanski A, Grinspoon S. Prevalence of hypogonadism among men with weight loss related to human immunodeficiency virus infections who were receiving hightly active antiretroviral therapy. Clin Infect Dis. 2000;31(5): 1240-1244.

45. Arora S, Agrawal M, Sun L, Duffoo F, Zaidi M, Iqbal J. HIV and bone loss. Curr Osteoporos Rep. 2010;8(4):219-226.

46. World Health Organization. AIDS Epidemic Update: December 2003. Geneva, Switzerland: UNAIDS. Available at: http://www.who.int/hiv/ pub/epidemioloy/epi2003/en. Accessed June 9, 2011.

47. Sepkowitz K. AIDS - the first 20 years. N Engl J Med. 2001;344(23): 1764-1772.

48. Sansone GR, Frengley JD. Impact of HAART on causes of death of persons with late-stage AIDS. J Urban Health. 2000;77(2):166-175.

49. Arpadi S, Horlick M, Thornton J, Cuff P, Wang J, Quezada S. Decreases in total body bone mineral content progress with age in HIV-infected children. In: Program Abstr 8th Conf Retrovir Oppor Infect Conf Retrovir Oppor Infect 8th 2001 Chic Ill. 2001 Feb 4-8;8:278 (abstract no. LB8).

50. Carr A. Osteopenia in HIV infection. National AIDS Treatment advocacy project. www.natap.org/2000/lipo/osteopenia011501.htm. 2000.

51. Carr A. Cardiovascular risk factors in HIV-infected patients. J Acquir Immune Defic Syndr. 2003;34(Suppl 1):S73-78.
52. Thompson PD, Buchner D, Pina IL, et al. Exercise and physical activity in the prevention and treatment of atherosclerotic cardiovascular disease: a statement from the Council on Clinical Cardiology (Subcommittee on Exercise, Rehabilitation, and Prevention) and the Council on Nutrition, Physical Activity, and Metabolism (Subcommittee on Physical Activity). Circulation. 2003;107(24):3109-3116.

53. Scevola D, Di Matteo A, Lanzarini P, et al. Effect of exercise and strength training on cardiovascular status in HIV-infected patients receiving highly active antiretroviral therapy. AIDS. 2003;17(Suppl 1): S123-S129.

54. Little P, Margetts B. The importance of diet and physical activity in the treatment of conditions managed in general practice. Br J Gen Pract. 1996;46(404):187-192.

55. Jovine MS, Buchalla CM, Santarém ÉM, Santarém JM, Aldrighi JM. Efeito do treinamento resistido sobre a osteoporose após a menopausa: estudo de atualização/Effect of resistance training on postmenopausal osteoporosis: update. Rev Bras Epidemiol. 2006;9(4):493-505.

56. Lirani G, Rebucci AP, Lazaretti CM. Abordagem física para prevenção e tratamento de osteoporose. Arq Bras Endocrinol Metabol. 2010;54(2):171-178.
HIV/AIDS - Research and Palliative Care

\section{Publish your work in this journal}

HIV/AIDS - Research and Palliative Care is an international, peerreviewed open-access journal focusing on advances in research in HIV, its clinical progression and management options including antiviral treatment, palliative care and public healthcare policies to control viral spread. The journal welcomes original research, basic science,

\section{Dovepress}

clinical \& epidemiological studies, reviews \& evaluations, expert opinion \& commentary, case reports \& extended reports. The manuscript management system is completely online and includes a very quick and fair peer-review system. Visit http://www.dovepress.com/ testimonials.php to read real quotes from published authors. 